\title{
Elementos para uma reflexão sobre tradução a partir da teoria benvenisteana da enunciação
}

\author{
Heloisa Monteiro Rosário ${ }^{1}$
}

Résumé: Dans le but de contribuer aux études sur la traduction et à la réflexion sur son enseignement, le présent travail aborde la pratique traductive et le rôle du traducteur à la lumière de la théorie de 1 fénonciation de Benveniste (Benveniste, 1966, 1974). Après une présentation de la notion de compétence en traduction (Hurtado Albir, 2001, 2005), nous proposons de situer la discussion dans le champ énonciatif en vue $d$ fanalyser la lecture spécifique réalisée par le traducteur au cours de son travail. Enfin, nous mettons l'accent sur les notions benvenistiennes de sémiotique, sémantique, appareil et cadre formel de réalisation de l fénonciation en lien avec la traduction, de manière à définir le cadre formel énonciatif de réalisation du texte traduit et, conséquemment, penser 1 fénonciation traductive.

Mots-clés: Traduction, Énonciation, mode sémiotique/mode sémantique, appareil et cadre formel de réalisation de l'énonciation, énonciation traductive

Resumo: Buscando contribuir não apenas para os estudos de tradução, mas também para uma reflexão sobre seu ensino, este trabalho reflete sobre a prática tradutória e o papel do tradutor considerados a partir da teoria benvenistiana da enunciação (Benveniste, 1966, 1974). Para tanto, apresentamos a noção de competência tradutória (Hurtado Albir, 2001, 2005) e, deslocando a discussão para o campo enunciativo, problematizamos a leitura específica realizada pelo tradutor em seu trabalho. Por fim, relacionando-as com a tradução, apresentamos as noções de semiótico, semântico, aparelho e quadro formal de realização da enunciação de Benveniste, propondo que se defina em que consiste o quadro formal enunciativo de realização do texto traduzido a fim de se pensar a enunciação tradutória.

Palavras-chave: Tradução, Enunciação, modo semiótico/modo semântico, aparelho e quadro formal de realização da enunciação, enunciação tradutória

1 Professora de língua francesa e tradução do Instituto de Letras da Universidade Federal do Rio Grande do Sul (UFRGS). 
Traduzir um texto não é traduzir a língua, mas traduzir um texto em sua própria língua.

Henri Meschonnic

\section{0 ponto de vista criando o objeto}

Traduzir o signo em vez de traduzir o poema é desescrever.

Fica, portanto, claro que escrever supõe repensar toda a teoria da linguagem. E que traduzir é a prática que, mais do que qualquer outra, coloca-a em jogo.

A conclusão disso é que o que está em jogo no traduzir é transformar toda a teoria da linguagem. Sim, uma verdadeira revolução cultural. (2007, p. 82, tradução nossa.)

Partindo dessa passagem de Henri Meschonnic sobre o traduzir, o presente trabalho busca contribuir para os estudos de tradução, de um lado, e para uma reflexão sobre o ensino da tradução, de outro, propondo uma discussão sobre a prática tradutória e o papel do tradutor considerados desde um ponto de vista enunciativo: o da teoria benvenistiana da enunciação (cf. Benveniste, 1966, 1974).

Em Émile Benveniste, l'invention du discours, Gérard Dessons afirma que: "Entre as aberturas que a teoria de Benveniste pôde suscitar, a mais interessante, pelo alcance de suas investigações, é certamente a teoria do ritmo elaborada por Henri Meschonnic" (2006, p. 179, tradução nossa).

Tradutor e teórico da tradução, Meschonnic busca a enunciação para pensar a tradução. $\mathrm{O}$ autor baseia-se fundamentalmente na reflexão de Benveniste sobre a noção de ritmo - desenvolvida no texto "La notion de 'rythme' dans son expression linguistique" (1951), publicado em Problèmes de linguistique générale, 1, em 1966² - e nos conceitos de semiótico e semântico por ele apresentados. Benveniste define o ritmo como "um verdadeiro interpretante antropológico" (Dessons, 2006, p. 182, tradução nossa), considerando-o a partir do nível semântico da língua. E é justamente através do nível semântico da teoria da linguagem proposta por Benveniste que Meschonnic relaciona a linguística da enunciação e o trabalho de historicização da noção de ritmo (Dessons, op. cit., p. 183), defendendo que toda tradução é uma "re-enunciação específica de um sujeito histórico" (1973, p. 305, tradução nossa). ${ }^{3}$

Daí por que, para o autor, "traduzir o signo em vez de traduzir o poema é desescrever". Ao traduzir, portanto, o tradutor não trabalha com a língua - "o signo" (o conjunto dos signos) -, mas com a língua em uso - "o poema" -, marcando-se em seu dizer, re-enunciando, em sua própria língua, o semantismo do original.

Escolhemos, desse modo, a teoria benvenistiana da enunciação como nosso ponto de vista pelo fato de "prever na língua o lugar da irrepetibilidade dela mesma", pois "a enunciação é sempre única e irrepetível, porque a cada vez que a língua é enunciada tem-se condições de tempo (agora), espaço (aqui) e pessoa (eu/tu) singulares" (Flores \& Teixeira, 2005 , p. 100), o que nos permite pensar o objeto tradução relacionando língua, sentido e contexto - aqui entendido como a situação discursiva na qual se podem identificar marcas de tempo, espaço e pessoa. Com isso, propomos um olhar enunciativo sobre a prática tradutória e o papel do tradutor.

2 Referimos aqui os títulos e as datas originais das publicações de Benveniste; no entanto, as citações seguem as traduções brasileiras.

3 Meschonnic retoma os conceitos de semiótico e semântico em Critique du rythme: Anthropologie historique du langage (1982), obra na qual formula sua teoria do ritmo. 
Iniciamos nosso texto discutindo a noção de competência tradutória tal como é apresentada por Amparo Hurtado Albir, também teórica da tradução. Em seguida, deslocamos a discussão para o campo enunciativo, problematizando a leitura específica realizada pelo tradutor em seu trabalho. E, por fim, apresentamos as noções de semiótico, semântico, aparelho e quadro formal de realização da enunciação de Benveniste; noções que fundamentam o que é, também para nós, o traduzir.

\subsection{Entrelaçando um pouco mais os dois campos}

Buscamos, incialmente, no campo dos estudos de tradução, algumas noções apresentadas por Hurtado Albir $(2001,2005)$ para refletirmos sobre a prática tradutória e o papel do tradutor.

A autora define a tradução como "um processo interpretativo e comunicativo que consiste na reformulação de um texto com os meios de outra língua e que se desenvolve em um contexto social e com uma finalidade determinada" (2001, p. 41, tradução nossa), sendo, desse modo, ao mesmo tempo, um ato de comunicação, uma operação textual e uma atividade cognitiva.

Hurtado Albir também salienta que a tradução não se situa no plano da língua e que não traduzimos unidades isoladas, descontextualizadas, mas sim textos ${ }^{4}$; não se podendo esquecer, por outro lado, que se trata da atividade de um sujeito - o tradutor - que necessita de uma competência especializada - a competência tradutória - e que este, ao traduzir, efetua um complexo processo mental que consiste em compreender o sentido para, depois, reformulá-lo com os meios da outra língua, levando sempre em conta as necessidades do destinatário e a finalidade da tradução (Op. cit., p. 41).

A competência tradutória, tal como é definida pela autora, difere da competência bilíngue (2005, p. 27), ou seja, para ser tradutor, não basta ser proficiente em diferentes idiomas, uma vez que "a competência tradutória é um conhecimento especializado, integrado por um conjunto de conhecimentos e habilidades, que singulariza o tradutor e $o$ diferencia de outros falantes bilíngues não tradutores" (Op. cit., p. 19). A teórica igualmente acrescenta que, por ser um conhecimento especializado, a competência tradutória não é inata, sendo adquirida por meio da aprendizagem 5 .

Hurtado Albir mostra ainda que o modo de traduzir muda ao longo da história: "a época em que se faz a tradução e o meio sociocultural de chegada condicionam as escolhas do tradutor, o tipo de relação que este estabelece com o texto original e as soluções adotadas" (2001, p. 210-211, tradução nossa) ${ }^{6}$. Além do contexto sócio-histórico, segundo a autora, a equivalência tradutória também depende de condicionamentos textuais, da finalidade e da modalidade da tradução.

Com isso, percebemos que - mesmo no campo dos estudos de tradução, a partir de teóricos como Hurtado Albir por exemplo - podemos dizer que o sujeito (o tradutor),

4 Trata-se, portanto, segundo a autora, de uma operação entre textos e não entre línguas. O que pode ser explicado através das noções benvenistianas de semiótico e semântico; noções que apresentamos no item 2.1 do presente trabalho.

5 Daí a importância de se discutir e de se buscar uma formação consistente para o profissional da tradução (o que passa, inclusive, por uma qualificação dos currículos de Bacharelado em Letras). Nesse sentido, torna-se central, por exemplo, a compreensão não apenas do que é, mas também do funcionamento do que denominamos, na conclusão deste trabalho, enunciação tradutória.

6 Recuperamos, neste ponto, Meschonnic para quem toda tradução é uma "re-enunciação específica de um sujeito histórico" (1973, p. 305, tradução nossa). E também Benveniste, visto que temos aqui um euem um aqui-agoradeterminados. 


\section{Conexão Letras}

através de suas escolhas, da relação estabelecida com o original e das soluções adotadas, singulariza-se, marcando-se em seu texto.

Deslocando a discussão para o campo enunciativo, constatamos que - desse ponto de vista - a tradução é um tema pouco ou quase nada explorado, o que se comprova, por exemplo, na obra Introdução à lingüística da enunciação, de Flores \& Teixeira (2005), que apresenta, em linhas gerais, as relações entre a linguística da enunciação e outras áreas do conhecimento - tais como: literatura, filosofia, psicanálise, análise de discurso, patologia da linguagem, descrição linguística, linguagem e trabalho, texto -, sem mencionar qualquer relação com os estudos de tradução.

No entanto, uma articulação entre esses dois campos é possível e muito mais do

que bem-vinda. É o que traz, aliás, Paula Nunes em seu estudo "Do bilíngüe ao tradutor, do enunciado à enunciação: notas sobre uma perspectiva enunciativa do tradutor e da tradução" (2009).

Nele a autora examina a noção de competência tradutória de Hurtado Albir para problematizar a leitura específica realizada pelo tradutor em seu trabalho, propondo que

o que ocorre (ou deveria ocorrer) na tradução é justamente uma "desautomatização" da leitura [...]. Isso porque se o processo tradutório implica competências e tomadas de decisão por parte do tradutor [...], esse processo dificilmente pode ser automático, uma vez que cada texto exige decisões diferentes, que só podem ser tomadas a partir da leitura do tradutor. (Op. cit., p. 3)

Nunes, desse modo, estabelece a distinção entre "ler o enunciado" e "ler a enunciação" de um texto a ser traduzido, defendendo que desautomatizar a leitura significa "ir além da materialidade do texto, suspeitar da transparência do enunciado, passando a interrogar-lhe como produto de uma enunciação, resultado, portanto, de uma articulação particular de forma e sentido, produzida pelo autor do original" (Op. cit., p. 5). Acrescentando ainda que, através dessa "leitura da enunciação" (isto é, da desautomatização de sua leitura do original), o sujeito tradutor produz uma nova enunciação - que é a tradução -, a autora salienta que se trata de um "uso subjetivo, particular e instanciado da linguagem", referindo-se sempre a um $e u$ inscrito em um determinado aqui-agora (Op. cit., p. 5).

A partir dessas considerações - e com o objetivo de continuar a discussão -, trazemos, a seguir, algumas noções da teoria benvenistiana da enunciação.

\subsection{0 referencial teórico benvenistiano}

Nosso ponto de vista neste trabalho é, assim, o da linguística da enunciação, através de uma reflexão fundamentada sobretudo nas noções de semiótico, semântico, aparelho e quadro formal de realização da enunciação apresentadas por Benveniste. Vamos a elas!

\section{Sobre as noções de semiótico e semântico}

Benveniste formula os conceitos de semiótico e semântico nos textos "La forme et le sens dans le langage" (1966) e "Sémiologie de la langue" (1969), ambos publicados em Problèmes de linguistique générale, 2, em 1974. No entanto, no texto "Les niveaux de l'analyse linguistique" (1962), publicado em Problèmes de linguistique générale, 1, em 1966, o autor já identifica dois diferentes níveis de análise - o da língua como sistema de signos e o da língua como instrumento de comunicação (1995, p. 139). 
Diz Benveniste em "La forme et le sens dans le langage" (1966):

O sentido a transmitir, ou se se quiser, a mensagem é definida, delimitada, organizada por meio das palavras; e o sentido das palavras, por seu turno, se determina em relação ao contexto de situação. Ora, as palavras, instrumentos da expressão semântica, são materialmente os signos do repertório semiótico. Mas estes signos, em si mesmos conceptuais, genéricos, não circunstanciais, devem ser utilizados como "palavras" para noções sempre particulares, específicas, circunstanciais, nas acepções contingentes do discurso. Isto explica porque os signos menos delimitados no interior do repertório semiótico da língua, como "ser", "fazer", "coisa", "isto" tenham como palavras a mais alta freqüência de emprego. De mais, a conversão do pensamento em discurso se assujeita à estrutura formal do idioma considerado, isto é, à organização tipológica que, segundo a língua, faz predominar tanto o gramatical quanto o lexical. No entanto, falando grosseiramente, o fato de que se pode "dizer a mesma coisa" numa como noutra categoria de idiomas é a prova, por sua vez, da independência relativa do pensamento e ao mesmo tempo de sua modelagem estreita na estrutura lingüística.

A reflexão sobre este fato notável parece clarear a articulação teórica que nós nos esforçamos por estabelecer. Pode-se transpor o semantismo de uma língua para o de uma outra,"salva veritate"; é a possibilidade da tradução; mas não se pode transpor o semioticismo de uma língua para o de uma outra; é a impossibilidade da tradução. Atinge-se aqui a diferença entre o semiótico e o semântico. (1989, p. 232-233)

Para o autor, a significação do sistema que é a língua articula-se então em duas dimensões: a do modo semiótico e a do modo semântico (Op. cit., p. 64-66).

O modo semiótico corresponde ao modo de significação próprio ao signo linguístico, definindo-se por uma relação de paradigma (Benveniste, op. cit., p. 230); ou seja, um signo de um determinado sistema define-se negativa e opositivamente em relação aos demais signos do mesmo sistema. Trata-se de um modo de significação que "se estabelece intrassistema, mediante distinção" (Flores et al., 2009, p. 206), sem qualquer relação com a exterioridade - o sujeito e o mundo. A referência aqui é interna ao sistema de signos.

Por outro lado, o modo semântico corresponde ao modo de significação próprio à palavra - o signo em uso pelo locutor -, definindo-se por uma relação de sintagma (Benveniste, 1989, p. 230); ou seja, o sentido de uma palavra define-se em relação ao seu emprego na frase, à organização sintática dos "elementos do enunciado destinado a transmitir um sentido dado, numa circunstância dada” (Op. cit., p. 230). Trata-se de um modo de significação do "sistema linguístico que resulta da inserção do sujeito na língua" (Flores et al., 2009, p. 205), visto que o sentido da palavra depende do contexto de situação, da situação discursiva na qual se pode identificar a inscrição do sujeito na língua através de marcas de tempo, espaço e pessoa. A referência continua, portanto, sendo interna, mas agora é interna ao próprio ato de enunciação, pois é "na e pela enunciação que o 'mundo' passa a existir” (Flores \& Mello, 2009, p. 201). Mais uma vez, então, não há qualquer relação com a exterioridade.

A partir disso, Benveniste afirma que não se pode traduzir o semioticismo de uma língua para o de uma outra, uma vez que o sentido de um signo dá-se intrassistema, sendo um sistema linguístico completamente independente de outro sistema; enquanto a priori se pode traduzir o semantismo de uma língua para o de uma outra, uma vez que o que se traduz é o sentido de um determinado enunciado produzido por um eu em um dado aquiagora. Eis por que, segundo Benveniste, "o semiótico (o signo) deve ser RECONHECIDO; 


\section{Conexão Letras}

o semântico (o discurso) deve ser COMPREENDIDO” (1989, p. 66)7.

Desse modo, em "La forme et le sens dans le langage", Benveniste diferencia os modos semiótico e semântico da língua e os relaciona com a tradução. Sendo, aliás, cabe ressaltar, a única vez em que o autor fala sobre tradução em seus textos.

\subsection{Sobre o aparelho e o quadro formal de realização da enunciação}

Em "L'appareil formel de l'énonciation" (1970), publicado em Problèmes de linguistique générale, 2, em 1974, Benveniste trata das noções de aparelho e quadro formal de realização da enunciação.

Neste texto, o autor retoma o conceito de enunciação - "este colocar em funcionamento a língua por um ato individual de utilização" (1989, p. 82) -, salientando que "é preciso ter cuidado com a condição específica da enunciação: é o ato mesmo de produzir um enunciado, e não o texto do enunciado, que é nosso objeto" (Op. cit., p. 82). Desse modo, para se estudar a enunciação, toma-se como objeto de estudo o enunciado ou, mais especificamente, a inscrição do sujeito na língua através de marcas de tempo, espaço e pessoa.

Por isso, segundo Benveniste, é preciso diferenciar o emprego das formas do emprego da língua. E, para tanto, propõe-se a "definir a enunciação no quadro formal de sua realização", esboçando "no interior da língua, os caracteres formais da enunciação a partir da manifestação individual que ela atualiza" (Op. cit., p. 83). O locutor, ao apropriarse da língua - isto é, dos recursos linguísticos disponíveis no sistema -, apropria-se então de um aparelho formal através do qual "enuncia sua posição de locutor por meio de índices específicos, de um lado, e por meio de procedimentos acessórios, de outro" (Benveniste, op. cit., p. 84).

Nesse processo de apropriação da língua, o locutor (o eu):

a) Instaura imediatamente um outro que, em sua alocução, será o alocutário (o tu). O alocutário, por sua vez, quando toma a palavra, também toma o lugar de locutor, havendo assim uma relação de reversibilidade entre o eu e o tu. Para Benveniste, portanto, a língua em funcionamento existe apenas na perspectiva do eu em relação ao tu que o constitui. Logo, "é porque existe intersubjetividade [o tu] que se pode pensar em subjetividade [no eu]" (Flores \& Mello, 2009, p. 200). Tem-se aqui o que o autor denomina o "quadro figurativo da enunciação", formado por duas figuras igualmente necessárias e reversíveis - uma origem e outra fim da enunciação - que instauram a estrutura do diálogo (1989, p. 87).

b) Instaura-se em sua fala e sua presença "faz com que cada instância de discurso constitua um centro de referência interno" (Benveniste, op. cit., p. 84) a partir do qual se estabelece o sentido do seu dizer.

Os índices específicos apontados por Benveniste são os índices de pessoa (a relação eu-tu) e os índices de ostensão - ou seja, os indicadores de subjetividade como pronomes, advérbios, adjetivos. Esses indicadores, mobilizados pelo locutor para marcar sua presença no discurso, significam em relação ao aqui-agora do locutor; daí a irrepetibilidade da enunciação, visto que as categorias de tempo, espaço e pessoa são - a cada instância de discurso - únicas, não podendo ser perenizadas no uso da língua. Eis por que 'o 'eu', o

7 Lembramos que, a esse respeito, Hurtado Albir afirma que - em seu trabalho de tradução - o tradutor realiza um complexo processo mental que consiste primeiro em compreender o sentido para, depois, reformulá-lo (reenunciá-lo, do ponto de vista enunciativo) com os meios da outra língua (rever item 1. deste texto).

8 Neste artigo, o autor também afirma que o processo enunciativo pode ser estudado sob, pelo menos, dois outros aspectos principais - o da realização vocal da língua e o da semantização da língua -, além do que se refere ao quadro formal de sua realização. 
'aquele', o 'amanhã' da descrição gramatical não são senão os 'nomes' metalingüísticos de eu, aquele, amanhã produzidos na enunciação” (Benveniste, op. cit., p. 86).

Já os procedimentos acessórios referidos pelo autor envolvem um "aparelho de funções", assim "além das formas que comanda [o aparelho formal], a enunciação fornece as condições necessárias às grandes funções sintáticas” (Op. cit., p. 86), tais como:
a) a interrogação - uma enunciação que suscita uma resposta;
b) a intimação - uma enunciação que implica uma reação do outro;
c) a asserção - uma enunciação que comunica uma certeza;
d) a modalização e a fraseologia - formas de uma enunciação que mostram as atitudes do enunciador em relação ao que enuncia;
e) a comunhão fática - uma enunciação que estabelece uma interação com o outro, cumprindo uma função social na qual "os laços de união [entre locutor e alocutário] são criados pela mera troca de palavras" (Benveniste, op. cit., p. 89).

A noção de temporalidade, por sua vez, também é retomada neste texto por Benveniste. Tratada em diversos outros artigos publicados em Problèmes de linguistique générale, 1, em 1966, o autor reitera aqui que "ela é produzida, na verdade, na e pela enunciação", que "o homem não dispõe de nenhum outro meio de viver o 'agora' e de torná-lo atual senão realizando-o pela inserção do discurso no mundo" (Op. cit., p. 85).

Desse modo, assim como pronomes, advérbios e adjetivos, as formas temporais igualmente definem-se em relação ao eu - o centro de referência da enunciação -, o tempo presente sendo então o presente de quem fala a cada nova instância de discurso.

Benveniste, por fim, encerra seu texto dizendo que seria preciso distinguir a "enunciação falada" da "enunciação escrita". Para o autor, a enunciação escrita situa-se em dois planos, uma vez que "o que escreve se enuncia ao escrever e, no interior de sua escrita, ele faz os indivíduos enunciarem” (Op. cit., p. 90).

$\mathrm{O}$ autor refere-se aqui à construção da narrativa e mostra que, através do quadro formal por ele esboçado, abrem-se amplas possibilidades de análise de formas complexas do discurso.

Deslocando um pouco essas considerações de Benveniste, acreditamos que temos também na tradução - igualmente uma "enunciação escrita" - uma forma complexa do discurso, visto que, de um lado, no original, temos as marcas do sujeito autor do texto e, de outro, em sua tradução, temos, do mesmo modo, a inscrição do sujeito tradutor que, ao traduzir, marca-se em seu dizer, re-enunciando, em sua própria língua, o semantismo do original. Acreditamos que as marcas que constituem o original não são simplesmente apagadas na tradução, mas se somam, de algum modo, às deixadas pelo sujeito tradutor do texto. Sujeito autor e sujeito tradutor encontram-se, portanto, na tradução.

Assim, para nós, temos aqui - também, mas não exatamente da mesma forma aventada por Benveniste em relação à narrativa - dois planos distintos que devem ser considerados quando se pensa a tradução. É o que propomos a seguir.

\section{CONCLUINDO}

Relacionando língua, sentido e contexto - aqui entendido como a situação discursiva na qual se podem identificar marcas de tempo (agora), espaço (aqui) e pessoa (eu/tu) singulares -, defendemos, no presente trabalho, um olhar enunciativo sobre a tradução. 
Para tanto, do campo dos estudos de tradução, mobilizamos a noção de competência tradutória (Hurtado Albir, 2001, 2005) e, a partir dela, deslocando a discussão para o campo enunciativo, problematizamos a leitura específica realizada pelo tradutor em seu trabalho, através da noção de desautomatização da leitura (Nunes, 2009).

Por sua vez, as categorias do campo enunciativo com as quais trabalhamos são as noções de modo semiótico e modo semântico tal como foram apresentadas por Benveniste, nos textos "Les niveaux de l'analyse linguistique" (1962) (PLG1), "La forme et le sens dans le langage" (1966) e "Sémiologie de la langue" (1969) (PLG2). Além das noções de aparelho e quadro formal de realização da enunciação apresentadas por Benveniste no texto "L'appareil formel de l'énonciation" (1970).

Articulando essas noções com nosso objeto que é a tradução, propomos que se defina em que consiste o quadro formal enunciativo de realização do texto traduzido a fim de se pensar a enunciação tradutória - uma forma complexa do discurso na qual se articulam dois planos distintos: o do sujeito autor e o do sujeito tradutor, ambos (o primeiro enunciando em uma língua e o segundo re-enunciando em sua própria língua o semantismo do original) deixando-se entrever através de marcas de tempo, espaço e pessoa em seus textos.

Nesse sentido, sustentamos que é preciso estabelecer - a exemplo do que faz Benveniste em "L'appareil formel de l'énonciation" (1970) - um aparelho formal de realização da tradução, especificando qual é o quadro figurativo da enunciação tradutória, qual é seu quadro formal e seu aparelho de funções. Ou seja, é preciso identificar as figuras envolvidas na enunciação tradutória e quais são as formas (os recursos linguísticos disponíveis no sistema) $)^{9}$ e as funções (os recursos sintáticos) das quais o sujeito tradutor se apropria em sua "enunciação escrita” específica que é uma tradução.

Desse modo, examinando - à luz da teoria benvenistiana da enunciação - a prática tradutória e o papel do tradutor, pretendemos contribuir tanto para os estudos de tradução quanto para uma reflexão sobre seu ensino. Este é o estudo que atualmente desenvolvemos, no Instituto de Letras da UFRGS, através de nosso trabalho de pesquisa.

\section{Referências}

BENVENISTE, Émile (1951). La notion de "rythme" dans son expression linguistique. In: _ (1966). Problèmes de linguistique générale, 1. Paris, Éditions Gallimard, p. $327-335,2006$.

. (1962). Les niveaux de l'analyse linguistique. In: . (1966). Problèmes de

linguistique générale, 1. Paris, Éditions Gallimard, p. 119-131, 2006. (1966). La forme et le sens dans le langage. In: (1974). Problèmes de linguistique générale, 2. Paris, Éditions Gallimard, p. 215-238, 2005.

\footnotetext{
9 Em relação às formas, como Flores \& Teixeira, consideramos que

o estudo da enunciação não está limitado a certos signos da língua, mas compreende a língua em sua totalidade. E nesse ponto seguimos de perto as idéias de Benveniste: se o aparelho formal de enunciação é constitutivo da língua, então ela mesma comporta referência ao seu próprio uso. Logo, todo e qualquer fenômeno lingüístico carrega em si a potencialidade de um estudo em termos de enunciação, já que sua existência depende do sujeito que o enuncia. O objeto da lingüística da enunciação é todo o mecanismo lingüístico cuja realização integra o seu próprio sentido e que se auto-referencia no uso. A enunciação é, pois, o que constitui esse processo. (2005, p. 106)

Por conseguinte, as formas às quais nos referimos aqui não se limitam aos "fenômenos lingüísticos circunscritos ao que Benveniste denominou de paradigma da pessoa" (Flores \& Teixeira, op. cit., p. 106), a saber: o estudo dos pronomes, adjetivos, verbos, advérbios, discurso relatado, implicitação e pressuposição.
} 
(1969). Sémiologie de la langue. In: . (1974). Problèmes de linguistique

générale, 2. Paris, Éditions Gallimard, p. 43-66, 2005.

. (1970). L'appareil formel de l'énonciation. In: . (1974). Problèmes de

linguistique générale, 2. Paris, Éditions Gallimard, p. 79-88, 2005.

. (1966). Problemas de lingüística geral I. Campinas, Pontes, 1995.

. (1974). Problemas de lingüística geral II. Campinas, Pontes, 1989.

DESSONS, Gérard. Émile Benveniste, l'invention du discours. Paris, Éditions IN PRESS, 2006.

FLORES, Valdir do Nascimento et al. Dicionário de Linguística da Enunciação. São Paulo, Contexto, 2009.

; TEIXEIRA, Marlene. Introdução à lingüística da enunciação. São Paulo, Contexto, 2005.

FLORES, Valdir do Nascimento; MELLO, Vera Helena Dentee de. Enunciação, texto, gramática e ensino de língua materna. In: Ciência \& Letras, Porto Alegre, Editora da FAPA, no. 45, p. 193-218, jan./jun. 2009.

HURTADO ALBIR, Amparo. Traducción y Traductología. Introducción a la Traductología. Madrid, Ediciones Cátedra, 2001.

.. A aquisição da competência tradutória: aspectos teóricos e didáticos. In:

PAGANO, A.; MAGALHÃES, C; ALVES, F. Competência e tradução. Cognição e discurso. Belo Horizonte, Editora UFMG, p. 15-57, 2005.

MESCHONNIC, Henri. Pour la poétique II. Épistémologie de l'écriture poétique de la traduction. Paris, Éditons Gallimard, 1973.

. (1982). Critique du rythme: Anthropologie historique du langage. Lagrasse, Éditons Verdier, 2009.

Éthique et politique du traduire. Lagrasse, Éditons Verdier, 2007.

NUNES, Paula Ávila. Do bilíngüe ao tradutor, do enunciado à enunciação:

notas sobre uma perspectiva enunciativa do tradutor e da tradução. Trabalho de conclusão da disciplina "Tópicos em tradução". Porto Alegre, PPG-Letras/UFRGS, 2009 . 